LAWRENCE LIVERMORE NAT IO N A L LABORATORY
Single-State Electronic Structure Measurements Using Time-Resolved X-Ray Laser Induced Photoelectron Spectroscopy

A. J. Nelson, J. Dunn, T. van Buuren, J. Hunter

November 30, 2004

2004 Materials Research Society Fall Meeting Boston, MA, United States November 29, 2004 through December 3, 2004 
This document was prepared as an account of work sponsored by an agency of the United States Government. Neither the United States Government nor the University of California nor any of their employees, makes any warranty, express or implied, or assumes any legal liability or responsibility for the accuracy, completeness, or usefulness of any information, apparatus, product, or process disclosed, or represents that its use would not infringe privately owned rights. Reference herein to any specific commercial product, process, or service by trade name, trademark, manufacturer, or otherwise, does not necessarily constitute or imply its endorsement, recommendation, or favoring by the United States Government or the University of California. The views and opinions of authors expressed herein do not necessarily state or reflect those of the United States Government or the University of California, and shall not be used for advertising or product endorsement purposes. 


\title{
Single-state electronic structure measurements using time-resolved $x$-ray laser induced photoelectron spectroscopy
}

\author{
A.J. Nelson, J. Dunn, T. van Buuren and J. Hunter \\ Lawrence Livermore National Laboratory, Livermore, CA 94551
}

\begin{abstract}
We demonstrate single-shot x-ray laser induced time-of-flight photoelectron spectroscopy on semiconductor and metal surfaces with picosecond time resolution. The LLNL COMET compact tabletop x-ray laser source provides the necessary high photon flux $\left(>10^{12} / \mathrm{pulse}\right)$, monochromaticity, picosecond pulse duration, and coherence for probing ultrafast changes in the chemical and electronic structure of these materials. Static valence band and shallow core-level photoemission spectra are presented for ambient temperature $\mathrm{Ge}(100)$ and polycrystalline $\mathrm{Cu}$ foils. Surface contamination was removed by UV ozone cleaning prior to analysis. In addition, the ultrafast nature of this technique lends itself to true single-state measurements of shocked and heated materials. Time-resolved electron time-of-flight photoemission results for ultra-thin $\mathrm{Cu}$ will be presented.
\end{abstract}

\section{INTRODUCTION}

Photoelectron spectroscopy is one of the preferred techniques for probing the static electronic structure of materials. This technique routinely uses synchrotron radiation or laboratory x-ray sources for photoionization, and various electron energy analyzers operating in a continuous mode. Time-of-flight (ToF) photoelectron spectroscopy (PES) with a pulsed synchrotron radiation source was first investigated as a means to determine energy and angular distributions in low photon energy regimes. [1] Researchers fairly recently started to use compact laser plasma x-ray sources (LPX) with $255 \mathrm{eV}, 2.5 \mathrm{~ns}$ duration x-ray pulses at a repetition rate of $10 \mathrm{~Hz}$ in conjunction with the ToF photolectron spectroscopy technique. They demonstrated sufficient energy resolution to observe static chemical shifts in the $\mathrm{Si} 2 \mathrm{p}$ photoemission for $\mathrm{SiO}_{2}$ and $\mathrm{Si}_{3} \mathrm{~N}_{4}$ using the time-of-flight technique after integrating for $\sim 100$ shots. $[2,3]$ The LPX ToF studies while successful have significant limitations which rule out a pump-probe experiment to study dynamic processes in a material induced by shocks, e.g. melting, phase changes. In particular, the low photon fluxes $\sim 2.5 \times 10^{8}$ photons/pulse on the sample required multiple shots to record a photoelectron spectrum.

Pushing towards observations of dynamical effects, a high harmonic generation (HHG) extreme ultraviolet (EUV) source coupled with a ToF spectrometer has been used in a number of pump-probe experiments. These have included semiconductor electron population dynamics as well as monitoring the surface chemical reaction of molecular oxygen and $\mathrm{CO}$ on $\mathrm{Pt}(111)$ with femtosecond time resolution. [4-6] These higher order harmonic sources have the advantage of shorter duration since the process is driven by ultrafast laser pulses, e.g. less than $60 \mathrm{fs}$, at a high repetition rate which makes them very attractive for dynamic pump-probe experiments. However, the presence of multiple harmonics requires further wavelength selection with multilayer-coated optics or a wavelength dispersive element and the lower photon fluence/shot requires multiple shots to achieve good signal statistics. 
We have been concentrating on the development of single-shot x-ray laser induced timeof-flight photoelectron spectroscopy as a potential optical pump - x-ray probe investigation of changes in the electronic structure of materials undergoing ultrafast laser heating. A pulsed x-ray laser source has many characteristics that are very important to the time-of-flight technique.

These include picosecond duration, highly monochromatic single line, high degree of coherence and sufficient photon fluence to record a complete photoelectron spectrum in a single shot. [7, 8] Recent results of valence band and shallow core electron spectra for static photoemission conditions for polycrystalline $\mathrm{Cu}$ and $\mathrm{Ge}(100)$ are presented here.

\section{EXPERIMENTAL}

The Ni-like Pd ion $4 d-4 p$ soft x-ray laser line at $14.7 \mathrm{~nm}(84.5 \mathrm{eV})$ is generated by two $1054 \mathrm{~nm}$ wavelength pump beams of the Compact Multipulse Terawatt (COMET) laser source [9]. This tabletop x-ray laser typically requires $5 \mathrm{~J}$ of laser pump energy and fires at a rate of 1 shot every 4 minutes. High $x$-ray photon numbers $\left(>10^{12} /\right.$ shot $)$, in a highly monochromatic line $\left(\mathrm{E} / \Delta \mathrm{E} \sim 4-5 \times 10^{4}\right)$, and with short $\sim 2-5 \mathrm{ps}$ pulse duration have been measured for this source [9-11]. When combined with small source area and beam divergence properties of the $14.7 \mathrm{~nm}$ line this gives ultra-high peak brightness $\sim 10^{24}-10^{25} \mathrm{ph} . \mathrm{mm}^{-2} \operatorname{mrad}^{-2} \mathrm{~s}^{-1}(0.1 \% \mathrm{BW})^{-1}$. Overall, the $14.7 \mathrm{~nm}$ peak brightness is $5-6$ orders of magnitude higher than $3^{\text {rd }}$ generation synchrotron undulator sources. However, these undulator sources still have higher average brightness of $0.5-$ $6 \times 10^{18} \mathrm{ph} \cdot \mathrm{mm}^{-2} \mathrm{mrad}^{-2} \mathrm{~s}^{-1}(0.1 \% \mathrm{BW})^{-1}$ at $50-10 \mathrm{~nm}$, respectively.

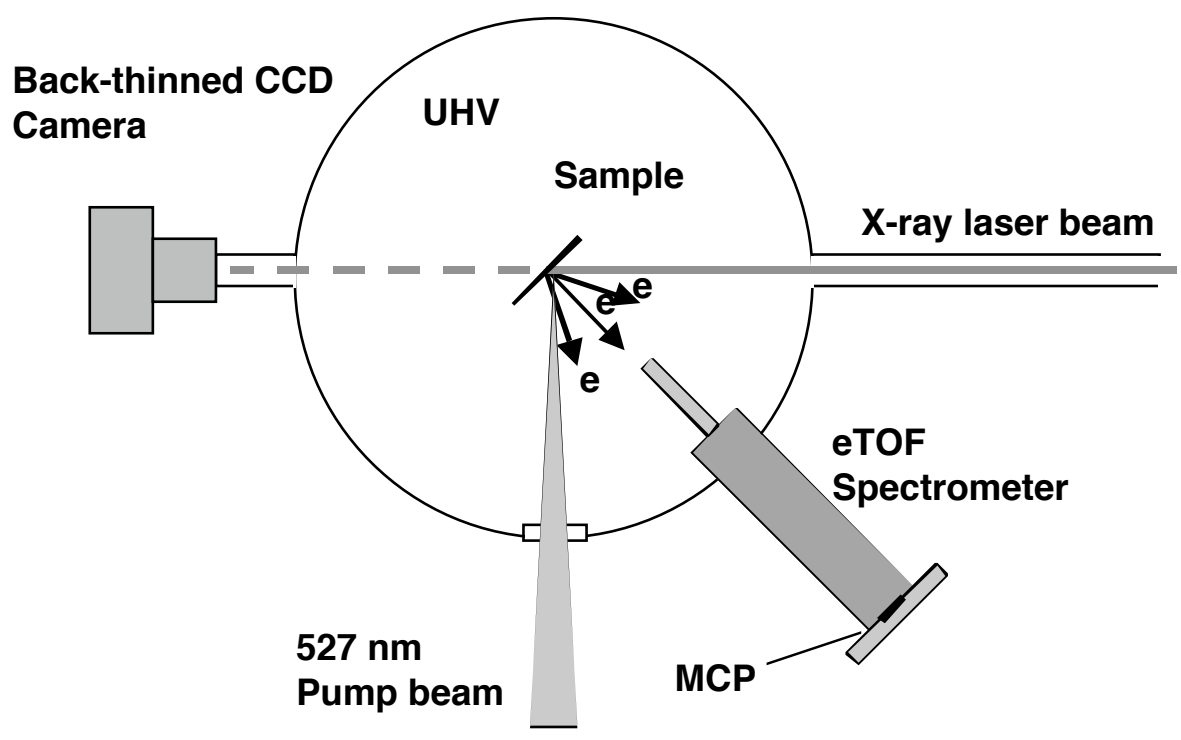

Figure 1. Schematic of the optical pump - x-ray laser induced time-of-flight photoemission probe of material surfaces.

Figure 1 shows a schematic of the x-ray laser photoelectron spectroscopy experimental setup. The X-ray laser probe is collimated by a normal incidence Mo:Si multilayer spherical mirror and relayed along the beamline by a $45^{\circ} \mathrm{Mo}: \mathrm{Si}$ multilayer flat mirror. The narrow reflectivity window of the mirrors selects the $\mathrm{x}$-ray laser wavelength and minimizes other plasma $\mathrm{x}$-rays reaching the sample. A pinhole or thin filter isolates the beamline from the experimental 
ultra-high vacuum (UHV) chamber, operating below $10^{-8}$ Torr. A fast optical laser beam can also be focused onto the sample to produce rapid heating and induce phase changes. Low energy photoelectrons, with K.E. $<84.5 \mathrm{eV}$, emitted from the valence band and shallow core levels are detected by a modified e-ToF spectrometer. [12] The signal is acquired and digitized using a fast 1 or $3 \mathrm{GHz}$ oscilloscope.

\section{RESULTS AND DISCUSSION}

Figure 2 presents the single-shot static e-ToF photoemission spectrum of the $3 d$ valence band of polycrystalline $\mathrm{Cu}$ illuminated with $10^{8}-10^{9} \mathrm{x}$-ray laser photons. Space charge effects were not evident at these intensities. The x-ray prompt peak seen in the spectrum with no drift voltage is generated from scattered $\mathrm{x}$-rays off the $\mathrm{Cu}$ foil surface hitting the micro-channel plate (MCP) detector a distance of $\mathrm{L}=43.75 \mathrm{~cm}$ away. [12] The x-ray prompt peak occurs $\mathrm{L} / \mathrm{c}=1.46$ ns after the $\mathrm{x}$-ray laser hits the sample, where $\mathrm{c}$ is the speed of light, and can be used as a timing fiducial. Since the mean escape depth of the photoemitted electrons is on the order of $\sim 1 \mathrm{~nm}$ for this kinetic energy, the spectrum should be more indicative of a $\mathrm{Cu}$-oxide layer in the absence of sputter ion cleaning. In addition, the photoelectron yield as given by $\mathrm{N}_{\mathrm{p}}=\mathrm{Fonn} \lambda \mathrm{T}$ can be estimated from the $\mathrm{x}$-ray fluence on the sample after filter and mirror losses $\left(\mathrm{F}=10^{9}\right.$ photons/pulse), the $\mathrm{Cu} 3 d$ photoionization cross-section $\left(\sigma \approx 8.712 \times 10^{-18} \mathrm{~cm}^{2}\right)$ [13], the $\mathrm{Cu}$ number density $\left(\mathrm{n}=8.4 \times 10^{22} \mathrm{~cm}^{-3}\right)$, the escape depth $\left(\lambda=5 \times 10^{-8} \mathrm{~cm}\right)$, and the angular collection efficiency of the MCP detector $\left(\mathrm{T}=2.5 \times 10^{-4}\right)$. Therefore, we can expect $9.1 \times 10^{3}$ photoelectrons/pulse to arrive at the MCP detector and produce signal. We observe single-shot photoelectron signals in the range of $1-2 \mathrm{~V}$ without the application of a retarding field.
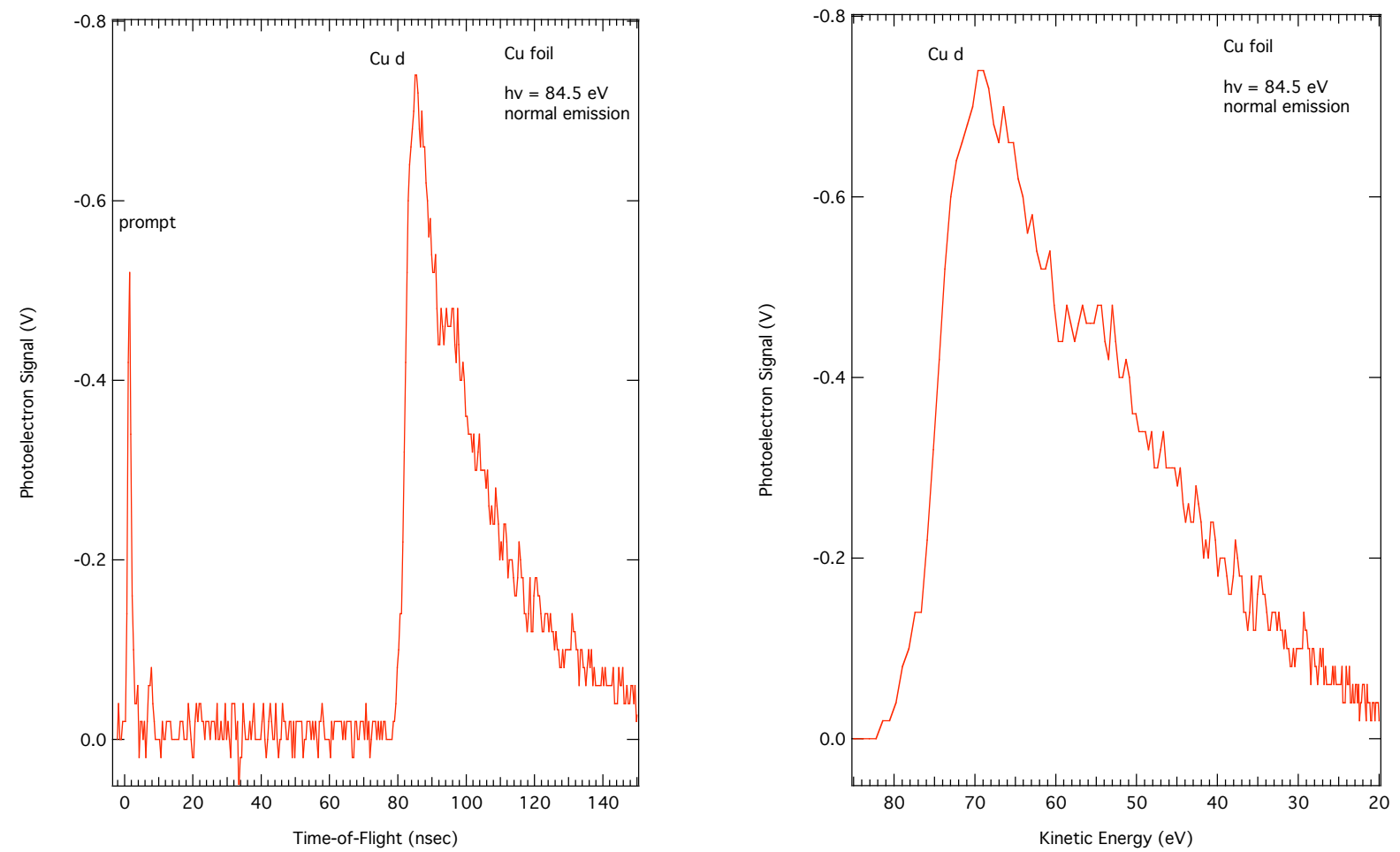

Figure 2. X-ray laser induced photoelectron spectra for polycrystalline $\mathrm{Cu}$ surface. 
Under static conditions the $3 d$ valence band electrons will have the highest kinetic energies as governed by $\mathrm{E}_{\mathrm{k}}=\mathrm{h} v-\mathrm{E}_{\mathrm{b}}-\phi$, where $\mathrm{h} v$ is the energy of the incident photon ( 84.5 $\mathrm{eV}), \mathrm{E}_{\mathrm{b}}$ is the binding energy of the photoelectron relative to the Fermi level and $\phi$ is the work function of the material $(\phi=4.6 \mathrm{eV}$ for $\mathrm{Cu})$. Also, the photoionization cross-section for the $\mathrm{Cu}$ $3 d$ shell at excitation energy of $80 \mathrm{eV}$ is $8.712 \mathrm{Mb}$. [13] Valence band photoemission will thus be the first and strongest event in the e-ToF spectrum. The strong $\mathrm{Cu} d$-state emission observed at the valence band maximum, i.e. first e-ToF event, is indicative of a high density of states (filled $d$-states) that are $2 \mathrm{eV}$ below the Fermi level. [14] The strong emission corresponds to direct transitions from $d$-like occupied bands to unoccupied bands above the Fermi energy. The initial as well as the final states determine the appearance, position, and intensity of these structures, and strongly depend on the applied photon energy. Non-equilibrium perturbations of the valence band states created by the $\mathrm{x}$-ray laser intensity $\left(10^{6} \mathrm{~W} / \mathrm{cm}^{2}\right)$ also contribute to the unusually abrupt electron energy distribution at the valence band edge. Displaying the ambient x-ray laser induced $\mathrm{Cu}$ valence band photoemission spectrum versus kinetic energy (Figure 2) yields an energy distribution curve that is qualitatively comparable to $\mathrm{Cu}$ valence band photoemission spectra presented in the literature [15] that were acquired using synchrotron radiation.

A second example of $\mathrm{x}$-ray laser induced photoemission is the static e-ToF spectra for the Ge (100) crystal presented in Figure 3. Each spectrum represents the average sum of two to four

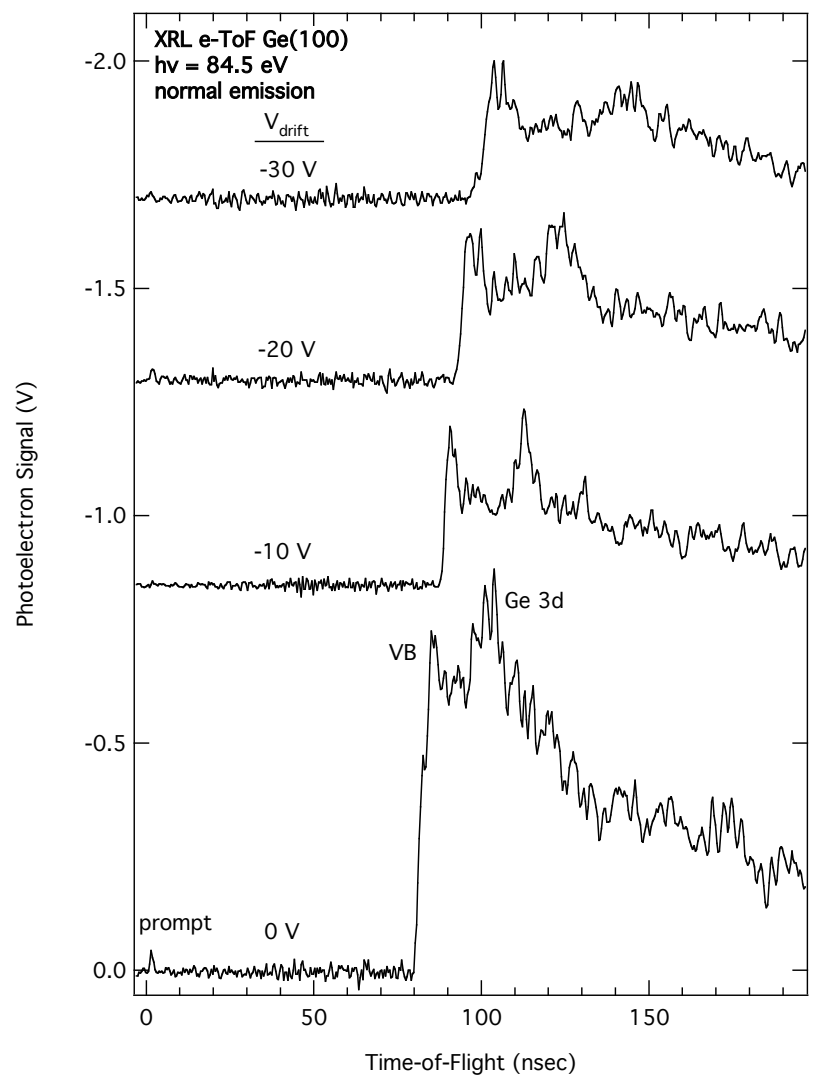

Figure 3. X-ray laser induced photoelectron spectra for $\mathrm{Ge}(100)$ surface using various drift voltages. 
shots and the retard (or drift) potentials were varied as shown on each spectrum to improve time resolution and consequently energy resolution. In this case, scattered x-rays off the polished Ge surface hitting the micro-channel plate (MCP) detector are responsible for the x-ray prompt peak. These spectra are more indicative of a Ge-oxide layer in the absence of sputter ion cleaning due to the $\sim 1 \mathrm{~nm}$ mean escape depth of the photoemitted electrons.

The upper valence band of oxidized Ge is composed primarily of Ge $4 p$ occupied states that hybridize with $\mathrm{O} 2 p$ states. [16] The work function for Ge (100) is $4.8 \mathrm{eV}$ and thus the kinetic energy for these valence band photoelectrons, the first e-ToF event, will be $\sim 79.7 \mathrm{eV}$. The kinetic energies of the Ge $3 d_{5 / 2,3 / 2}$ spin-orbit pair are $50.5 \mathrm{eV}$ and $50.0 \mathrm{eV}$, respectively, and are the next expected event in the spectrum. In addition, the photoionization cross-sections for the Ge $4 p$ valence band and the Ge $3 d$ shell at an excitation energy of $80 \mathrm{eV}$ are $0.039 \mathrm{Mb}$ and $6.999 \mathrm{Mb}$, respectively [13] which would imply that the strongest peak should be the Ge $3 d$ core. However, oxidized Ge has an $\mathrm{O} 2 p$ component in the valence band with a photoionization crosssection of $2.064 \mathrm{Mb}$ at an excitation energy of $80 \mathrm{eV}$. Therefore, based on the observed peak height ratios for valence band and Ge $3 d$ core-level emission, the spectra are indeed indicative of an oxidized surface layer. Non-equilibrium occupation of the valence band states created by the $\mathrm{x}$-ray laser intensity $\left(10^{6} \mathrm{~W} / \mathrm{cm}^{2}\right)$ may also contribute to the unusual electron energy distribution at the valence band edge. The broad background under the Ge $3 d$ peak originates from secondary electron emission that represents elastically and multiply scattered electrons.

As we increase the negative drift voltage in the flight tube of the e-ToF analyzer and thus reduce the kinetic energy of the photoemitted electrons, the valence band threshold and separation between the valence band and core-level events change (Fig. 3). The notable decrease in photoelectron signal for the $-30 \mathrm{~V}$ retarding field is due to a decrease in the effective solid angle of photoelectrons reaching the MCP detector. [2] In the case of no drift voltage, the photoelectron yield as given by $\mathrm{N}_{\mathrm{p}}=\mathrm{Forn} \lambda \mathrm{T}$ can be estimated from the x-ray fluence on the sample after filter and mirror losses $\left(\mathrm{F}=10^{9}\right.$ photons/pulse), the Ge $3 d$ photoionization crosssection $\left(\sigma \approx 7.0 \times 10^{-18} \mathrm{~cm}^{2}\right)$, the Ge number density $\left(\mathrm{n}=4.4 \times 10^{22} \mathrm{~cm}^{-3}\right)$, the escape depth $(\lambda=5$ $\left.\times 10^{-8} \mathrm{~cm}\right)$, and the angular collection efficiency of the MCP detector $\left(\mathrm{T}=2.5 \times 10^{-4}\right)$. Therefore, we can expect $3.9 \times 10^{3}$ photoelectrons/pulse to arrive at the MCP detector and produce signal. We observe single-shot photoelectron signals in the range of $200-400 \mathrm{mV}$ without retarding.

\section{CONCLUSIONS}

We have successfully validated $\mathrm{x}$-ray laser induced time-of-flight photoemission by measuring the valence band and shallow core-level photoemission in room temperature bulk materials. Single-shot spectra have been achieved showing that the incident photon number is more than enough for this application. Future work will include demonstration of the optical pump-x-ray probe characterization capability to observe the evolution of changes in chemical and electronic structure with picosecond time resolution during dynamic processes.

\section{ACKNOWLEDGEMENTS}

This work was performed under the auspices of the U.S. Dept. of Energy by the University of California Lawrence Livermore National Laboratory under Contract No. W-7405-Eng-48. 


\section{REFERENCES}

1. R.Z. Bachrach, F.C. Brown and S.B.M. Hagström, J. Vac. Sci. Technol. 12(1), 309 (1975).

2. H. Kondo, T. Tomie and H. Shimizu, Appl. Phys. Lett. 69(2), 182 (1996).

3. H. Kondo, T. Tomie and H. Shimizu, Appl. Phys. Lett. 72(21), 2688 (1998).

4. A. Rettenberger and R. Haight, Phys. Rev. Lett. 76, 1912 (1996).

5. M. Bauer, C. Lei, K. Read, R. Tobey, J. Gland, M. M. Murnane, and H. C. Kapteyn, Phys. Rev. Lett. 87(2), 025501-1 (2001).

6. G. Tsilimis, C. Benesch, J. Kutzner, and H. Zacharias, J. Opt. Soc. Am. B20(1), 246 (2003).

7. A.J. Nelson, J. Dunn, T. van Buuren, J. Hunter, R.F. Smith, O. Hemmers, and D.W. Lindle, Soft X-Ray Lasers and Applications V, ed. E.E. Fill et al, SPIE Proceedings 5197, 168 (2003).

8. J. Dunn, R.F. Smith, J. Nilsen, A.J. Nelson, T. Van Buuren, S.J. Moon, J.R. Hunter, J. Filevich, J.J. Rocca, M.C. Marconi, V.N. Shlyaptsev, X-Ray Lasers 2002: 8th International Conference on X-ray Lasers, ed. J.J. Rocca et al, AIP Conference Proceedings No. 641, 481 (2002).

9. J. Dunn, Y. Li, A. L. Osterheld, J. Nilsen, J. R. Hunter, and V. N. Shlyaptsev, Phys. Rev. Lett. 84, 4834 (2000).

10. R.F. Smith, J. Dunn, J. R. Hunter, J. Nilsen, S. Hubert, S. Jacquemot, C. Remond, R. Marmoret, M. Fajardo, P. Zeitoun, L. Vanbostal, C. L.S. Lewis, M. Francoise Ravet, F. Delmotte, Opt. Lett. 28(22), 2261 (2003).

11. J. Dunn et al., Soft x-ray lasers and Applications V, SPIE Int. Soc. Opt. Eng. Proc, vol. 5197, ed. E.E. Fill and S. Suckewer, 51-59 (2003).

12. O. Hemmers, S.B. Whitfield, P. Glans, H. Wang, D.W. Lindle, R. Wehlitz, and, I.A. Sellin, Rev. Sci. Instrum. 69, 3809 (1998).

13. J.-J. Yeh and I. Lindau, "Atomic Subshell Photoionization Cross Sections and Asymmetry Parameters: $1 \leq \mathrm{Z} \leq 103$ ", Atomic Data and Nuclear Data Tables 32, 11 (1985).

14. N. Smith, Phys. Rev. B3, 1862 (1971).

15. J. Stöhr, F.R. McFeely, G. Apai, P.S. Wehner and D.A. Shirley, Phys. Rev. B14, 4431 (1976).

16. A. Goldoni, A. Santoni, M. Sancrotti, V.R. Dhanak and S. Modesti, Surf. Sci. 382, 336 (1997). 